\title{
Spatiotemporal simulation and predication of heavy metal(loid) concentrations in coal chemical industrial areas with a soil environmental capacity model
}

\author{
Kai Zhang ${ }^{1} \cdot$ Jiajun Yang $^{1} \cdot$ Yuning $\mathrm{Ji}^{1} \cdot \mathrm{Yu} \mathrm{Xia}^{1}$
}

Received: 5 July 2018/Revised: 20 August 2018/ Accepted: 19 September 2018/Published online: 9 October 2018

(C) The Author(s) 2018

\begin{abstract}
Heavy metal (loid) (HM) accumulation in the soil and the HM spatiotemporal distribution have important implication for soil pollution prevention and remediation. The present study investigated the concentrations and spatiotemporal distributions of lead $(\mathrm{Pb})$, mercury $(\mathrm{Hg})$, cadmium $(\mathrm{Cd})$, chromium $(\mathrm{Cr})$ and arsenic $(\mathrm{As})$ in the topsoil of a coal chemical plant in Ningxia Autonomous region (Ningxia), China. Topsoil samples $(n=153)$ were obtained using the checkerboard method, and the HM concentrations were determined. The soil residual rates of the five HMs were measured with leaching experiments and were applied in a soil environmental capacity model to predict the quantitative variation of the HM concentrations. The predicted results were employed to estimate the HM spatiotemporal distribution within 20 years with the Kriging technique. The number of sampling sites, where all five HM concentrations exceed their corresponding background values in Ningxia, would be increased from 0 to $90 \%$ within 10 years of the plant operation. In addition, $\mathrm{Pb}$ and $\mathrm{Cd}$ were distributed along the traffic routes. Mercury and As were distributed near fuel gas emission vents. Chromium was mainly accumulated in slag dumps. The study may provide the theoretical and practical foundation for future HM pollution control in coal chemical plants.
\end{abstract}

Keywords Coal chemical plant $\cdot$ Soil $\cdot$ Heavy metal (loid) $\cdot$ Kriging $\cdot$ Simulation prediction

\section{Introduction}

The modern coal chemical industry has been developed rapidly with the increasing energy demand due to the economy development (Xia and Han 2017). However, it has drawn great attention that the coal chemical industry uses tremendous energy and water, and produces lots of pollution (Liu et al. 2017). Heavy metals metal (loid)s (HMs) are major pollutants in the coal chemical industry, and they can enter the environment with wastewater, gas emission, and solid residuals (Wang 2012). Soil is the main media of HM deposit, and the accumulated HM in the soils may pose human health risks through chronic exposures

Yu Xia

clairexia617@163.com

1 School of Chemistry and Environment, China University of Mining and Technology (Beijing), Beijing 100083, China
(Wang et al. 2012). Previous studies reported that HMs can be toxic, carcinogenic and teratogenic, and about $90 \%$ of human carcinogens were caused by the uptake of or exposure to high concentrations of HMs and other chemicals for a long period of time (Yi et al. 2011; An et al. 2016). China's Prevention and Control of Heavy Metal Pollution in the 12th Five-Year Plan claimed that $\mathrm{Pb}, \mathrm{Hg}$, $\mathrm{Cd}, \mathrm{Cr}$ and As were classified as main pollutants in China. Therefore, it is of great significance to know the concentrations of the five HMs and their changing tendencies in coal chemical plants and make the corresponding preventive measures. Particularly, Cr mainly exists as $\mathrm{Cr}(\mathrm{III})$ and $\mathrm{Cr}(\mathrm{VI})$ in the soil (Stewart et al. 2003), and $\mathrm{Cr}(\mathrm{VI})$ can cause worse adverse effects on humans than $\mathrm{Cr}$ (III) (Wu et al. 2016; Liang et al. 2000). Therefore, the present study mainly focused on $\mathrm{Cr}(\mathrm{VI})$.

The commonly used models to predict HM concentrations can be roughly divided into the flux prediction model, the two-stage cumulative rate estimation model, the spatial 
distribution prediction model at different times and the mathematical prediction model based on Hazen probability curve ( $\mathrm{Li}$ et al. 2014). The soil environmental capacity model, which is one of the commonly used models for predicting HM accumulation in the soil, uses the material balance principle to deduce the kinetic equation of the soil pollution process (Wang et al. 1993). Zhao et al. (1999) analyzed the parameters of the model and applied the model to investigate the changing tendencies of HMs under different conditions. Lin (2009) used the soil environmental capacity model to forecast the HM concentrations in the soil of a developed industrial city in the south of Guangdong province and obtained the trends of the HM concentrations in the city under the optimistic, normal, and pessimistic scenarios. Chen (2014) used the model to predict the HM concentrations in the soil and obtained the HM spatial distributions in the study area in 2020. However, current studies mainly aimed at urban or agricultural soils and other large sites, few reported heavy metal prediction in a single industrial area, especially in the coal chemical industry.

In the present study, based on the soil environmental capacity model, the Kriging method was adopted to construct spatiotemporal graphs of the HM distributions in the soil and determined the changing tendencies of HM concentrations at different production units. The study can provide the theoretical and practical basis for the prevention and control of the HM pollution in coal chemical plants.

\section{Materials and methods}

\subsection{Research area profile}

The coal chemical plant is located in the northeastern part of Ningxia Autonomous Region (Ningxia) (Fig. 1a). The plant trial operation was conducted at the end of 2010, and the plant was officially put into operation at the end of 2011. The terrain of the plant location is relatively smooth and flat with a slope less than $10^{\circ}$. The soil type in the study site is mainly sierozem (China National Environmental Monitoring Centre, 1990). The plant is in the hinterland of the mainland and has the typical continental monsoon climate. The NW wind is prevalent during the whole year with a frequency of $25.8 \%$, followed by the SSE wind with a frequency of $25.5 \%$. The NW wind speed is significantly higher than the SSE wind, thus the NW wind has greater transportation capacity than the SSE wind.

A top view of the study area was obtained by the remote sensing technique (Fig. 1b).The top view can be divided into ten functional units (Fig. 1c). During the operation, the coal is added in the coal corridor from the southeast corner
Fig. 1 The study site: a Geographical location. b Remote sensing aerial map of the plant. c Schematic diagram of the plant layout

and then transported into the power unit and the gasification unit. Separate slag dumps are in service for the power unit and gasification unit in the north. Three chimneys are in operation at the southeast corner of the power unit. The product is mainly transported by railway and a small amount by the highway.

\subsection{Soil sampling}

Soil samples were collected in July 2014. The chessboard method (Liu 1987) was used to sample the soil with the spacing of $50 \mathrm{~m} \times 50 \mathrm{~m}$, due to the gentle terrain of the study area and the difference in the concentration of soil pollutants in production units. Sampling points were offset or skipped when they were located in the pools, buildings, slag dumps and other locations inconvenient for sampling. The coordinates of sampling points were recorded using the global positioning system (GPS) (Fig. 2a, b). Topsoil samples $(0-20 \mathrm{~cm})$ were collected and air-dried at room temperature. After removing rocks and foreign debris, all samples were ground and passed through a $0.15 \mathrm{~mm}$ nylon sieve. The prepared soil samples were sealed in sampling bottles for later analysis.

\subsection{The leaching experiment}

A leaching experiment was conducted to obtain the residual rates of the HMs in the soil, which provided important parameters for the soil environmental capacity model in the later section. The $\mathrm{pH}$ of the rainwater of the target area is between 6.37 and 7.67, according to the weather bureau of Ningxia Province. Therefore, acid leaching experiment was not involved in this study.

The topsoil from sampling site 1 was used as the uncontaminated reference sample in the leaching experiment since this site was far away from the main production unit. Three Plexiglas leaching columns, with a length of $35 \mathrm{~cm}$, a diameter of $4 \mathrm{~cm}$, and a soil loading of about $0.8 \mathrm{~kg}$, were used. The procedure was as follows: (1) Lead nitrate, mercuric chloride, cadmium chloride, potassium dichromate and arsenic oxide were added to $0.3 \mathrm{~kg}$ reference soil at the concentrations of $10,5,5,50$ and $10 \mathrm{mg} / \mathrm{kg}$ soil for lead $(\mathrm{Pb})$, mercury $(\mathrm{Hg})$, cadmium $(\mathrm{Cd})$, chromium (VI) (Cr(VI)) and arsenic (As), respectively (Shangguan et al. 2015). The homogenized mixture was allowed to stand for 10 days and then used as the source of pollution. (2) The bottom of each leaching column was coated with a layer of absorbent cotton. Each column was 

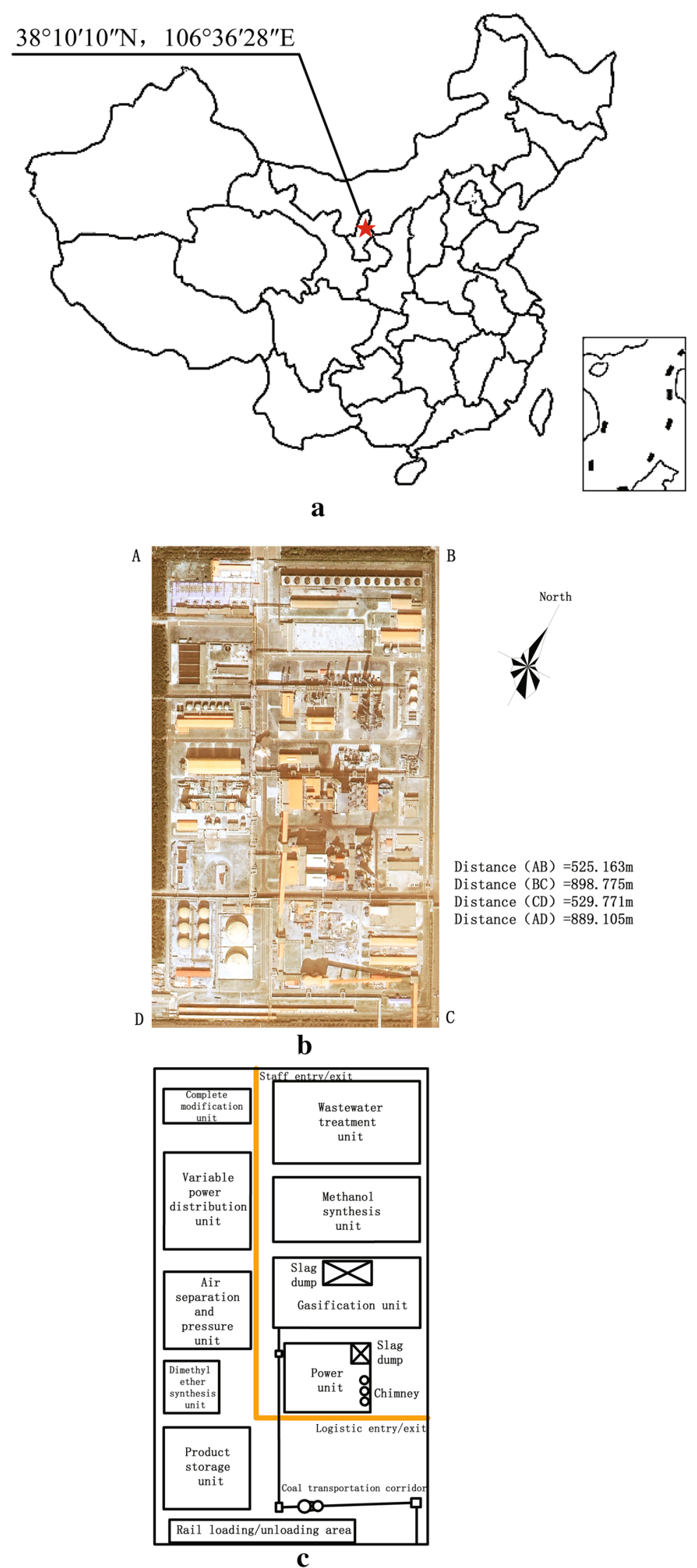


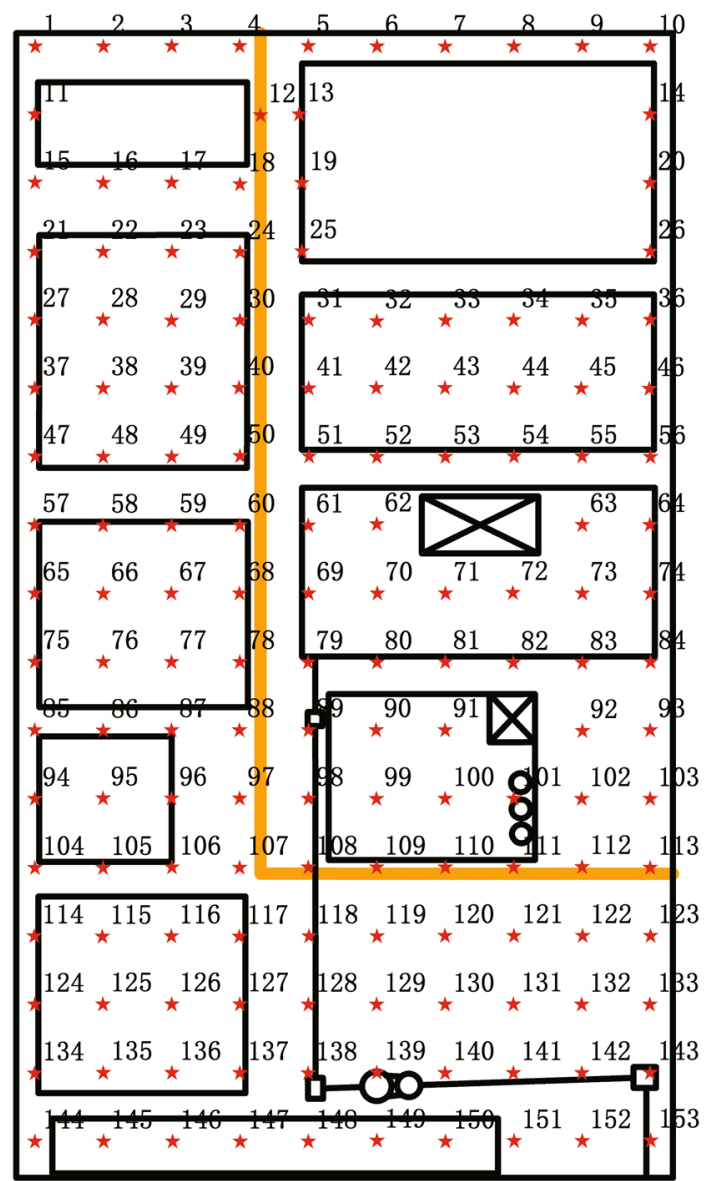

Fig. 2 Distribution of sampling points: the factory layout

packed with $0.5 \mathrm{~kg}$ uncontaminated soil, and $0.3 \mathrm{~kg}$ of the synthetic polluted soil obtained in the previous step was added. Finally, a layer of absorbent cotton was added on the top of the leaching column. (3) A peristaltic pump was connected to the column, and the down-flow rate was set at $0.4 \mathrm{ml} / \mathrm{min}$, with the experimental period of 15 days when all the water was estimated to flow out from the column. (4) Three soil samples ( $2 \mathrm{~g})$ were taken out of each column after well mixed at the end of leaching. The HM concentrations in the soil were measured. The soil residual rates of HMs were calculated as (Shangguan et al. 2015):

$K=\frac{\left(C_{1}-C_{0}\right) M_{0}}{M_{1}} \times 100 \%$

where $K$ is the soil residual rate (\%), $C_{1}$ is the HM concentration after leaching $(\mathrm{mg} / \mathrm{kg}), C_{0}$ is the HM concentration before leaching $(\mathrm{mg} / \mathrm{kg}), M_{0}$ is the mass of the soil $(\mathrm{kg})$, and $M_{1}$ is the mass of HM addition (mg).

\subsection{Sample analysis}

The prepared soil samples were digested with $\mathrm{HF}, \mathrm{HNO}_{3}$, and $\mathrm{H}_{2} \mathrm{O}_{2}$ in a microwave digestion system. The concentrations of $\mathrm{Pb}, \mathrm{Cd}, \mathrm{Cr}$, and $\mathrm{As}$ in the soil samples were then measured by inductively coupled plasma mass spectrometry (ICP-MS, Varian X series II). The Hg concentration was measured using a DMA-80 mercury analyzer (Milestone S.r.L).

\subsection{The soil environmental capacity model}

The soil environmental capacity model is the mathematical expression of the HM concentration change in soil environmental system (Xia 1989). The core formula is:

$Q_{n}=Q_{0} K+Q K \frac{1-K^{n}}{1-K}-Z \frac{K-K^{n}}{1-K}$

where $n$ is the target time period, $Q_{0}$ is the initial soil concentration $(\mathrm{mg} / \mathrm{kg}), Q_{n}$ is the soil concentration in the nth year $(\mathrm{mg} / \mathrm{kg}), K$ is the soil residual rate $(\%), Q$ is the annual input $(\mathrm{mg} / \mathrm{kg})$, and $Z$ is the annual output $(\mathrm{mg} / \mathrm{kg}$ ).

The formula (2) can be summarized as follows: the amount of soil concentration in the nth year $=$ the initial residue $+n$-year total amount of input - the $n$-year total amount of output. The following formula is obtained by merging the input and output:

$Q_{n}=B K^{n}+R K \frac{1-K^{n}}{1-\mathrm{K}}$

where $n$ is the target time period, $Q_{n}$ is the soil concentration in the nth year $(\mathrm{mg} / \mathrm{kg}), B$ is the soil background concentration $(\mathrm{mg} / \mathrm{kg}), K$ is the soil residual rate $(\%)$, and $R$ is the net annual input ( $\mathrm{mg} / \mathrm{kg}$ ).

Based on assumptions that the plant annual operation is stable, the annual discharge of pollutants (i.e. the annual input $R$ ) is constant, and soil properties in the plant do not change significantly (i.e., $K$ is constant), the annual input $R$ at the sampling point is:

$R=\frac{\left(Q_{n}-B K^{n}\right)(1-K)}{K\left(1-K^{n}\right)}$

After the $R$ at each sampling point was obtained (with the measured value in 2014 and the background value) and assumed to be constant, the $Q_{n}$ value at the nth year can be calculated by the formula (3). However, long-term forecasts are of little practical significance to industrial plants due to the variation in the coal quality and production process. Therefore, $n$ was given 10,15 , and 20 (i.e., the year 2021, 2026, and 2031), with the year 2011 as the offset.

\subsection{Kriging method}

The Kriging method, also known as the spatial local interpolation method, is based on spatial autocorrelation. The unknown sampling points of regional variables were 
estimated with linear, unbiased, optimal estimation of the interpolation method using the original data of regional variables and the structure of the semivariogram function (Tang and Yang 2006).The core formula is expressed as:

$Z\left(x_{0}\right)=\sum_{i=1}^{n} \lambda_{i} Z\left(x_{i}\right)$

where $Z\left(x_{0}\right)$ is the estimated point concentration $(\mathrm{mg} / \mathrm{kg})$, $n$ is the total number of sampling points, $Z\left(x_{i}\right)$ is the concentration of the $i$ point $(\mathrm{mg} / \mathrm{kg})$, and $\lambda_{i}$ is a set of weight coefficients. The core of the algorithm is to calculate the minimum unbiased estimate of $Z\left(x_{0}\right)$.

More details about the principal and process of this method were shown in a previous study (Zhang et al. 2018).

\subsection{Software platform}

SPSS19.0 software was used for descriptive statistical analysis and multiple stepwise regression analysis. GS+7.0 was used for semi-variance analysis, interactive semivariance analysis, and Kriging interpolation. ArcGIS10.0 was used for space autocorrelation analysis, map digitalization, mapping and cropping of interpolation results, and cross-validation.

\section{Results and discussion}

\subsection{Analysis of heavy metal concentration in the soil}

The HM background values were lower than those of Ningxia before the plant was put into operation (Table 1). The average concentrations of $\mathrm{Hg}, \mathrm{Cd}(\mathrm{VI})$ and As exceeded their Ningxia background values after plant operation for 3.5 years. The averages of $\mathrm{Hg}$ and $\mathrm{Cd}(0.092$ and $0.553 \mathrm{mg} / \mathrm{kg}$, respectively) were more than four times of the Ningxia background values $(0.021$ and $0.112 \mathrm{mg} / \mathrm{kg}$, respectively). Thus, the HMs, except for $\mathrm{Pb}$, were enriched in the coal chemical plant. In addition, $\mathrm{Pb}, \mathrm{Cr}(\mathrm{VI})$ and $\mathrm{As}$ had weak variation (coefficient of variation $<0.1$ ), while $\mathrm{Hg}$ and $\mathrm{Cd}$ had medium variation $(0.1<$ coefficient of variation < 1) (Zhu 1999). Therefore, $\mathrm{Pb}, \mathrm{Cr}$ and $\mathrm{As} \mathrm{had}$ low degrees of dispersion in the soil, indicating that they had relatively uniform distributions. $\mathrm{Hg}$ and $\mathrm{Cd}$, particularly $\mathrm{Hg}$, showed a higher degree of dispersion, indicating that the pollution areas of the two elements were more concentrated.

\subsection{Longitudinal migration characteristics of HMs in the soil}

The results of leaching experiments and the five HM residual rates in the soil are shown in Table 2. The residual rates of $\mathrm{Pb}, \mathrm{Hg}, \mathrm{Cd}$ and $\mathrm{As}$ in the soil were all above $90 \%$, in the order as $\mathrm{Pb}>\mathrm{As}>\mathrm{Hg}>\mathrm{Cd}$. However, the residual rate of $\mathrm{Cr}(\mathrm{VI})$ was less than $50 \%$, which was mainly due to its strong dissolution morphology and the strong migration capacity (Yang et al. 2014).

\subsection{Temporal changes of HM concentrations in the soil}

The annual inputs $(R)$ at the 153 sampling points were calculated by the derived formula (4) with the measured concentrations of the samples and the local background values (Table 3 ). The input $(R)$ of $\mathrm{Cr}(\mathrm{VI})$ had a weak variation, and the inputs $(R)$ for the other four HMs had a medium variation, which indicated that the five HM emissions varied greatly in different process units of the

Table 2 Metal concentrations in the soil samples from the leaching experiment

\begin{tabular}{lccccc}
\hline Metals & $C_{0}(\mathrm{mg} / \mathrm{kg})$ & $C_{1}(\mathrm{mg} / \mathrm{kg})$ & $M_{0}(\mathrm{~kg})$ & $M_{1}(\mathrm{mg})$ & $K(\%)$ \\
\hline $\mathrm{Pb}$ & 15.400 & 21.323 & 0.805 & 5 & 95.354 \\
$\mathrm{Hg}$ & 0.002 & 1.168 & 0.805 & 1 & 93.858 \\
$\mathrm{Cd}$ & 0.600 & 1.742 & 0.805 & 1 & 91.891 \\
$\mathrm{Cr}(\mathrm{VI})$ & 7.459 & 18.196 & 0.805 & 20 & 43.217 \\
$\mathrm{As}$ & 10.480 & 16.380 & 0.805 & 5 & 94.997 \\
\hline
\end{tabular}

Table 1 Statistical description of heavy metal concentrations in the topsoil samples from the coal chemical plant in Ningxia (2014)

\begin{tabular}{lcccccc}
\hline Metals & $\begin{array}{l}\text { Concentration } \\
\text { range/(mg/kg) }\end{array}$ & $\begin{array}{l}\text { Average } \\
\text { concentration/(mg/kg) }\end{array}$ & SD & $\begin{array}{l}\text { Coefficient of } \\
\text { variation }\end{array}$ & $\begin{array}{l}\text { Local background } \\
\text { value } /(\mathrm{mg} / \mathrm{kg})\end{array}$ & $\begin{array}{l}\text { Ningxia background } \\
\text { value } /(\mathrm{mg} / \mathrm{kg})\end{array}$ \\
\hline $\mathrm{Pb}$ & $14.810-19.210$ & 17.087 & 1.104 & 0.065 & 13.100 & 20.600 \\
$\mathrm{Hg}$ & $0.000-0.160$ & 0.092 & 0.038 & 0.413 & 0.007 & 0.021 \\
$\mathrm{Cd}$ & $0.400-0.690$ & 0.553 & 0.065 & 0.118 & 0.102 & 0.112 \\
$\mathrm{Cr}{ }^{\mathrm{VI}}$ & $7.454-10.815$ & 9.437 & 0.875 & 0.093 & 4.424 & 6.060 \\
$\mathrm{As}$ & $10.480-16.010$ & 12.840 & 1.174 & 0.091 & 7.59 & 11.900 \\
\hline
\end{tabular}

Note ${ }^{\text {a } F r o m ~ t h e ~ E I A ~ r e p o r t ~ i n ~} 2009$.

${ }^{\mathrm{b}}$ From the China Environmental Monitoring Station in 1990. 
Table 3 Annual inputs at the sampling sites

\begin{tabular}{lcccl}
\hline Metals & Input $(\mathrm{mg} / \mathrm{kg})$ & $\begin{array}{l}\text { Average } \\
(\mathrm{mg} / \mathrm{kg})\end{array}$ & $\mathrm{SD}$ & $\begin{array}{l}\text { Coefficient of } \\
\text { variation }\end{array}$ \\
\hline $\mathrm{Pb}$ & $1.181-2.579$ & 1.903 & 0.348 & 0.183 \\
$\mathrm{Hg}$ & $-0.002-0.051$ & 0.029 & 0.012 & 0.414 \\
$\mathrm{Cd}$ & $0.112-0.212$ & 0.164 & 0.022 & 0.134 \\
$\mathrm{Cr}(\mathrm{VI})$ & $10.017-14.681$ & 12.768 & 1.214 & 0.095 \\
$\mathrm{As}$ & $1.325-3.097$ & 2.081 & 0.376 & 0.181 \\
\hline
\end{tabular}

plant. The annual input of $\mathrm{Cr}(\mathrm{VI})$ was over $10 \mathrm{mg} / \mathrm{kg}$, which was much higher than that of the other elements. Therefore, the $\operatorname{Cr}(\mathrm{VI})$ concentration in the soil increased rapidly at the initial operation stage of the plant. However, the $\mathrm{Cr}(\mathrm{VI})$ concentration in the topsoil would be quickly stabilized due to its low residual rate in the soil. At the same time, a large quantity of $\mathrm{Cr}(\mathrm{VI})$ could enter the deep soil, causing a threat to groundwater.

The HM concentrations in the year of 2021, 2026 and 2031 were estimated with the soil environmental capacity model (Table 4). The concentrations of $\mathrm{Hg}, \mathrm{Cd}, \mathrm{Cr}(\mathrm{VI})$ and As were all below the corresponding Ningxia background values in 2011, but over $90 \%$ of them would exceed their background values in 10 years (Table 4), indicating that
HMs were enriched quickly in the soil by the coal chemical production activities.

The enrichment rate of $\mathrm{Pb}$ was the lowest among the five HMs. The 10-year (from 2011 to 2021) enrichment rate was predicted to be $75.0 \%$, and the $\mathrm{Pb}$ concentration in more than $80 \%$ of the sampling sites would exceed the Ningxia background value. However, the $\mathrm{Pb}$ concentration in $98 \%$ of the sampling sites would reach $29.028 \mathrm{mg} / \mathrm{kg}$ on average in 2031, and the highest concentration would be about two times of the Ningxia background value. On the whole, the enrichment rate of $\mathrm{Pb}$ in the soil is relatively low, but $\mathrm{Pb}$ has a great enrichment tendency in the topsoil due to the high residual rate.

The concentrations of $\mathrm{Hg}$ and $\mathrm{Cd}$ was estimated to be increasing rapidly, and the average values in 2021 were predicted to be significantly higher than their corresponding Ningxia background values. The $\mathrm{Hg}$ concentration would increase by about 28.7 times from 2011 to 2021, and $\mathrm{Cd}$ concentration would increase by nearly 10 times. The enrichment rates of the two elements were $29.8 \%$ and $23.5 \%$, respectively, from 2021 to 2026 . However, the enrichment rates from 2026 to 2031 were predicted to be decreased to $16.7 \%$ and $12.5 \%$, respectively. Overall, $\mathrm{Hg}$ and $\mathrm{Cd}$ were enriched rapidly in the soil.

Table 4 Simulated temporal changes of the HM concentrations in the soil

\begin{tabular}{|c|c|c|c|c|c|}
\hline Metals & Year & $\begin{array}{l}\text { Concentration }^{\mathrm{a}} \\
(\mathrm{mg} / \mathrm{kg})\end{array}$ & $\begin{array}{l}\text { Average } \\
(\mathrm{mg} / \mathrm{kg})\end{array}$ & $\begin{array}{l}\text { Ningxia } \\
\text { background values }^{b} \\
(\mathrm{mg} / \mathrm{kg})\end{array}$ & $\begin{array}{l}\text { Percentage } \\
\text { exceeding the } \\
\text { background }(\%)\end{array}$ \\
\hline \multirow[t]{4}{*}{$\mathrm{Pb}$} & 2011 & $12.800-13.700$ & 13.100 & 20.600 & 0 \\
\hline & 2021 & $17.321-28.180$ & 22.923 & & 79.1 \\
\hline & 2026 & $18.787-33.421$ & 26.337 & & 96.1 \\
\hline & 2031 & $19.943-37.552$ & 29.028 & & 98.0 \\
\hline \multirow[t]{4}{*}{$\mathrm{Hg}$} & 2011 & $0.004-0.010$ & 0.007 & 0.021 & 0 \\
\hline & 2021 & $0-0.367$ & 0.208 & & 98.0 \\
\hline & 2026 & $0-0.478$ & 0.270 & & 98.0 \\
\hline & 2031 & $0-0.559$ & 0.315 & & 98.0 \\
\hline \multirow[t]{4}{*}{$\mathrm{Cd}$} & 2011 & $0.102-0.102$ & 0.102 & 0.112 & 0 \\
\hline & 2021 & $0.766-1.412$ & 1.107 & & 100 \\
\hline & 2026 & $0.938-1.752$ & 1.367 & & 100 \\
\hline & 2031 & $1.051-1.974$ & 1.538 & & 100 \\
\hline \multirow[t]{4}{*}{$\mathrm{Cr}(\mathrm{VI})$} & 2011 & $3.867-4.800$ & 4.424 & 6.060 & 0 \\
\hline & 2021 & $7.623-11.172$ & 9.716 & & 100 \\
\hline & 2026 & $7.624-11.173$ & 9.718 & & 100 \\
\hline & 2031 & $7.624-11.173$ & 9.718 & & 100 \\
\hline \multirow[t]{4}{*}{ As } & 2011 & $6.769-8.327$ & 7.590 & 11.900 & 0 \\
\hline & 2021 & $14.646-28.148$ & 20.408 & & 100 \\
\hline & 2026 & $17.027-35.085$ & 24.734 & & 100 \\
\hline & 2031 & $18.869-40.452$ & 28.081 & & 100 \\
\hline
\end{tabular}

Note ${ }^{\text {a }}$ The predicted concentration was set as 0 when the concentration of the heavy metal in the soil was negative.

${ }^{\mathrm{b}}$ From China National Environmental Monitoring Centre,1990. 
The topsoil concentration of $\mathrm{Cr}(\mathrm{VI})$ at all sampling sites exceeded the background value in five years, due to the high annual net input. However, the average concentration was predicted to be stabilized at $9.72 \mathrm{mg} / \mathrm{kg}$ in the topsoil because of the low soil residual rate of $\mathrm{Cr}(\mathrm{VI})$ (Table 2).

Similar to $\mathrm{Pb}$, the enrichment rate of As from 2011 to 2021 was predicted to be $168.9 \%$, and the percentage of sampling sites where the topsoil $\mathrm{Pb}$ exceeds the background value would increase from 0 to $100 \%$. The enrichment rates would decrease to $21.2 \%$ and $13.5 \%$, respectively, from 2021 to 2026 and from 2026 to 2031 .

\subsection{Spatial trend simulation and risk warning}

\subsubsection{Spatiotemporal change of $\mathrm{Pb}$ concentration and early warning}

The enrichment of $\mathrm{Pb}$ would first occur on both sides of the coal corridor and remain afterward (Fig. 3). In 2026, high level of $\mathrm{Pb}$ enrichment was predicted to occur on both sides of the trunk road, around the power unit chimney, and near the entrances and exits. In 2031, the enrichment would become more pronounced, concentrating on both sides of the corridor and near entrances and exits. Moreover, there would be a certain enrichment around the chimney of the power unit. Zhang et al. (2017) studied the Pb-enriched area in the coal chemical field and found that $\mathrm{Pb}$ emissions from coal chemical industry were relatively low, and the main enrichment area was located on both sides of the corridor and the highway. Zhu et al. studied the HM distribution on both sides of the highway suggesting that the use of leaded gasoline and $\mathrm{Pb}$-containing lubricants contributed to a large amount of $\mathrm{Pb}$ emissions, which could indicate that the main sources of $\mathrm{Pb}$ in the soil were the lubricant application in the corridor and the automobile exhaust (Zhu et al. 2015).

For the prevention and control of $\mathrm{Pb}$, vehicle exhaust emissions along the traffic should be well controlled, lubricating oil should be used reasonably, and the friction of the transmission belt should be reduced. In addition, it is necessary to take measures to protect the staff working in the coal corridor and personnel commuting through the entrance and exit.

\subsubsection{Spatiotemporal change of $\mathrm{Hg}$ concentration and early warning}

The first enrichment area of $\mathrm{Hg}$ was observed in the dynamic unit and its south side, and the high $\mathrm{Hg}$ concentration in the soil would spread out around this area (Fig. 4), which indicated the source of $\mathrm{Hg}$ in the plant area is relatively monotonic. However, the enrichment rate of $\mathrm{Hg}$ is relatively fast. The concentration of $\mathrm{Hg}$ at the core region would increase steadily at around $0.050 \mathrm{mg} / \mathrm{kg}$ every five years, while the enrichment rate of the surrounding area would decrease with the distance from the core region.

A study suggested that more than $90 \%$ of the $\mathrm{Hg}$ was discharged with the flue gas, due to the high temperature in the coal-fired boiler (Sun and Bai 2008). Another study found that almost all $\mathrm{Hg}$ in the coal was released at a temperature of $815^{\circ} \mathrm{C}$ (Zhang et al. 2003). Therefore, the
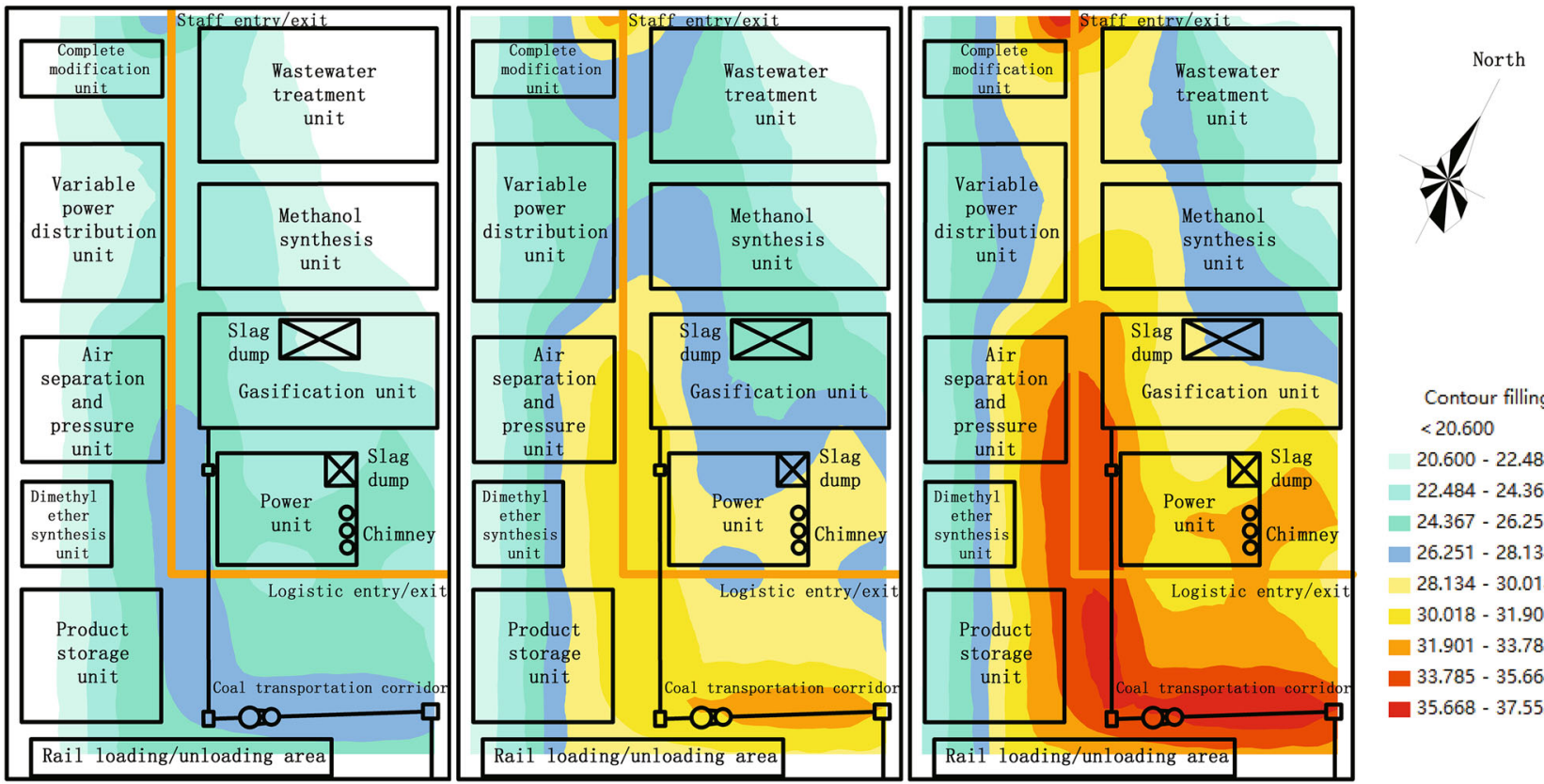

Fig. 3 Spatiotemporal distribution of $\mathrm{Pb}$ concentrations in the soil of the coal chemical factory (left to right for the year 2021, 2026 and 2031) 

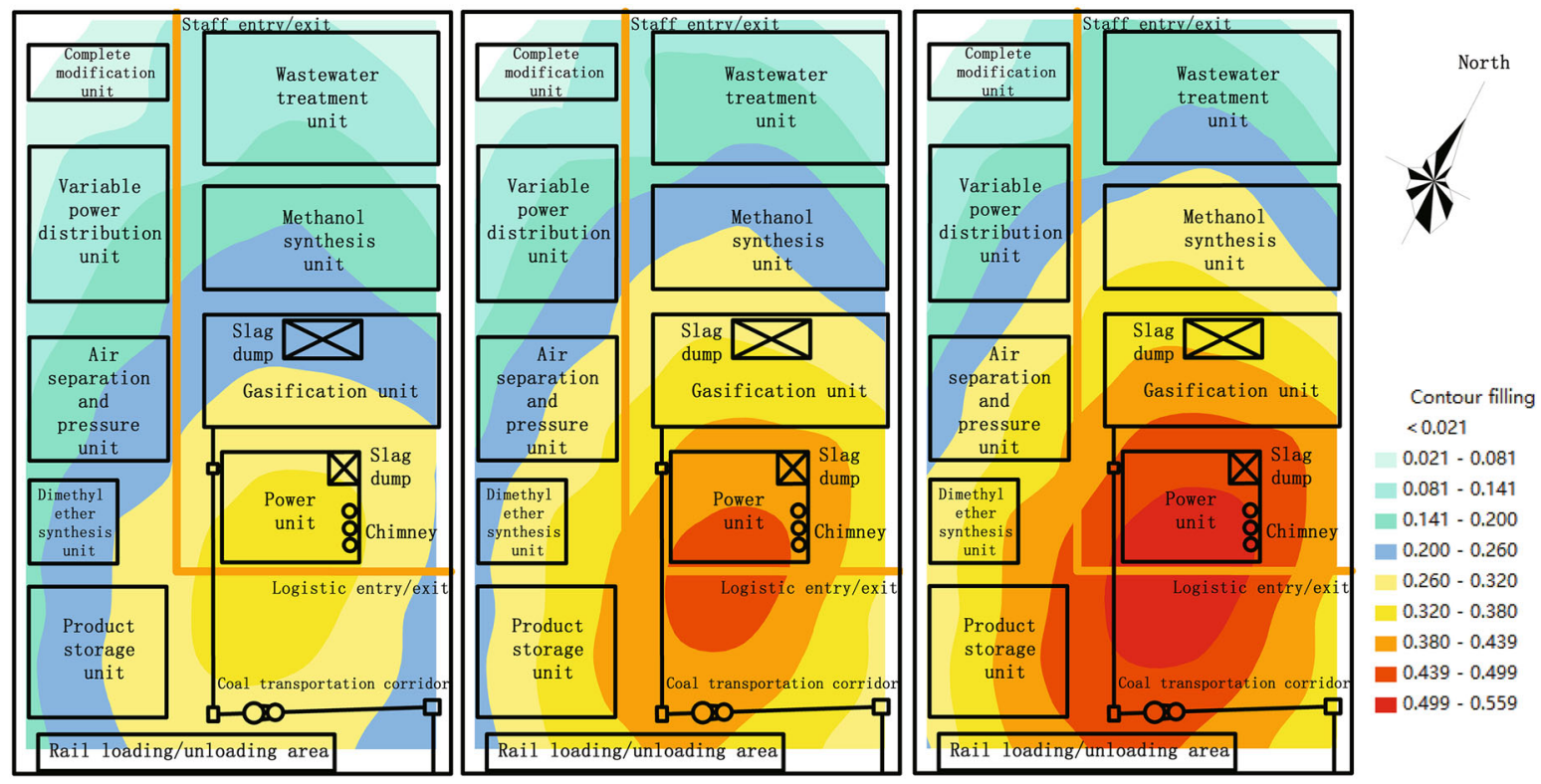

Fig. 4 Spatiotemporal distribution of $\mathrm{Hg}$ concentration in the soil of the coal chemical factory (left to right for the year 2021, 2026 and 2031)

soil $\mathrm{Hg}$ in the present study was predicted to mainly come from the gas emission of the power unit.

In terms of prevention and control of $\mathrm{Hg}$ in the plant area, the management of flue gas emissions in the plant area should be strengthened. Measures should be taken to protect staff members working under the flue gas discharge ports such as power units and logistics outlets.

\subsubsection{Spatiotemporal change of Cd concentration and early warning}

The core regions of the $\mathrm{Cd}$ enrichment were predicted to be located on both sides of the line from the northwest to the southeast of the plant and spread to farther distance (Fig. 5). These regions cover the main road in the factory, the downward direction of the flue gas discharge, and the coal corridor. In addition, the highest concentration of $\mathrm{Cd}$ would occur at the personnel entrance and exit and the coal corridor.

The main soil pollutant on both sides of the roads in Beijing was found to be $\mathrm{Cd}$, and the main sources were supposed to be the motor vehicle exhaust and dust generated by the abrasion and braking of motor vehicle tires (Wang 2014). A study suggested that a certain amount of Cd was emitted through flue gas during coal combustion (Xu et al. 2004). As a result, motor vehicles and coal-fired gas emissions were deducted to be the main Cd sources in the present study. By 2021, the highest concentrations of $\mathrm{Cd}$ would be concentrated around the personnel entrance and exit. By 2026, the first-line of Cd enrichment along the roadway-coal-coal corridor would be more noticeable, and the high concentration around the personnel entrance and exit will expand, and a core area will be formed along the coal corridor. By 2031, Cd high concentration area will cover both sides of the main road, the power unit, and the coal corridor. In general, $\mathrm{Cd}$ enrichment will be relatively fast and concentrated along the line of the personnel entrance and exit, the downwind of the flue gas vent-coal corridors.

To prevent and control $\mathrm{Cd}$ in the plant, the management of flue gas emission and the pollution control from traffic in the plant should be strengthened. Working along the coal corridors, near the personnel entrance and exit, and along the main roads, staff members should be protected from the hazard of $\mathrm{Cd}$ pollution.

\subsubsection{Spatiotemporal change of Cr(VI) concentration and early warning}

The highest soil $\mathrm{Cr}(\mathrm{VI})$ concentration in the plant was predicted to be located at the gasification unit and the power unit, and the concentration would decrease in a stepwise manner with the distance from the two units (Fig. 6). The estimated $\mathrm{Cr}(\mathrm{VI})$ concentration in the soil will exceed the Ningxia background value in the whole plant in 2021 , and the maximum exceedance will reach $184.32 \%$.

A study found that the $\mathrm{Cr}$ concentration in the gasification slag dumps in the coal chemical industry was significantly higher than that in raw coal and flue gas (Zhang et al. 2017). Another study resulted in finding that the volatilization temperature of $\mathrm{Cr}$ was over $1500{ }^{\circ} \mathrm{C}$, and the volatile amount was very low (Yang Li 2011). Therefore, the main source of $\mathrm{Cr}(\mathrm{VI})$ in the present study was 

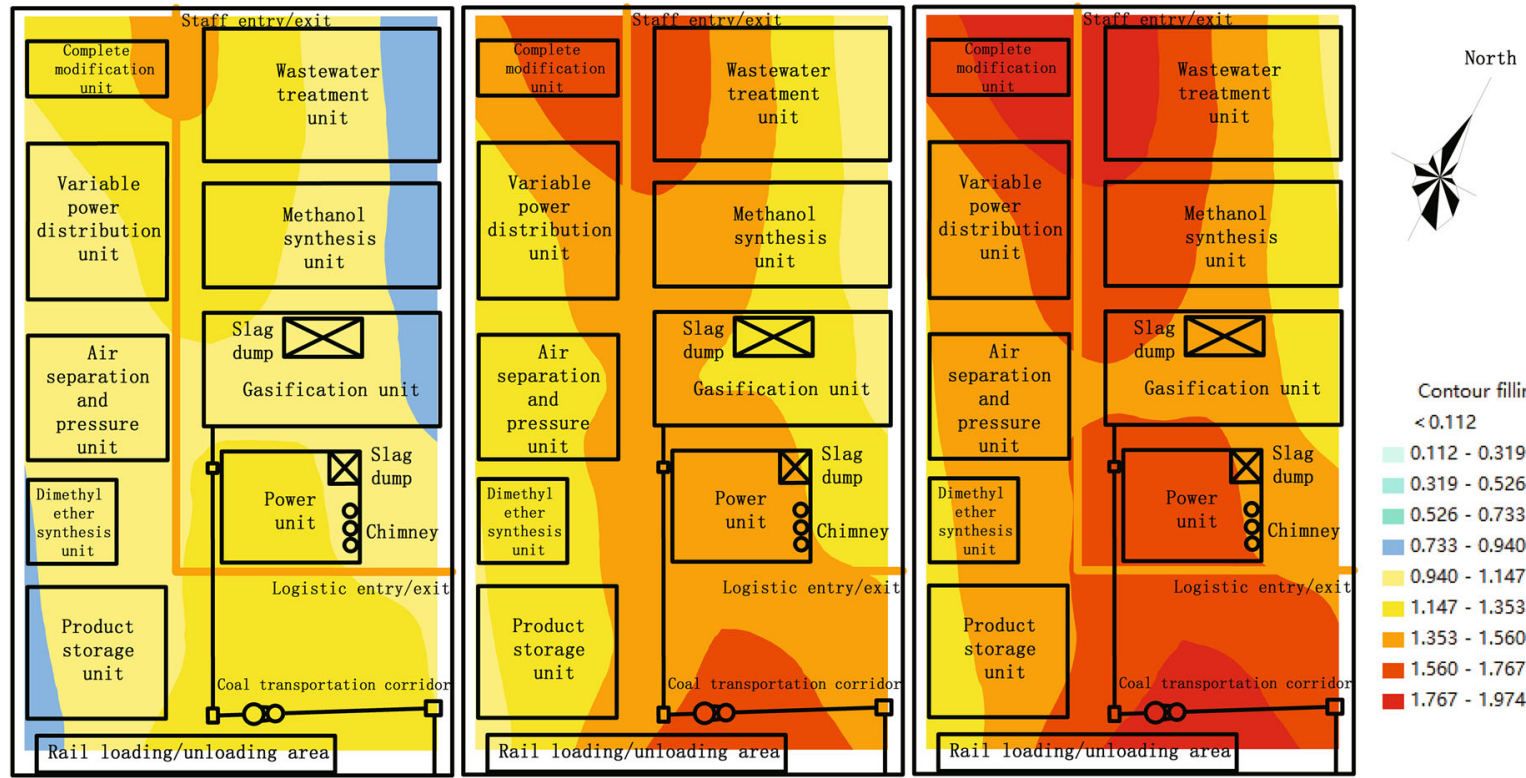

Contour filling

$<0.112$

$0.112-0.319$

$0.319-0.526$

$0.526-0.733$

- $0.733-0.940$

$0.940-1.147$

$1.147-1.353$

- $1.353-1.560$

$1.560-1.767$

- $1.767-1.974$

Fig. 5 Spatiotemporal distribution of Cd concentrations in the soil of the coal chemical factory (left to right for the year 2021,2026 and 2031 )
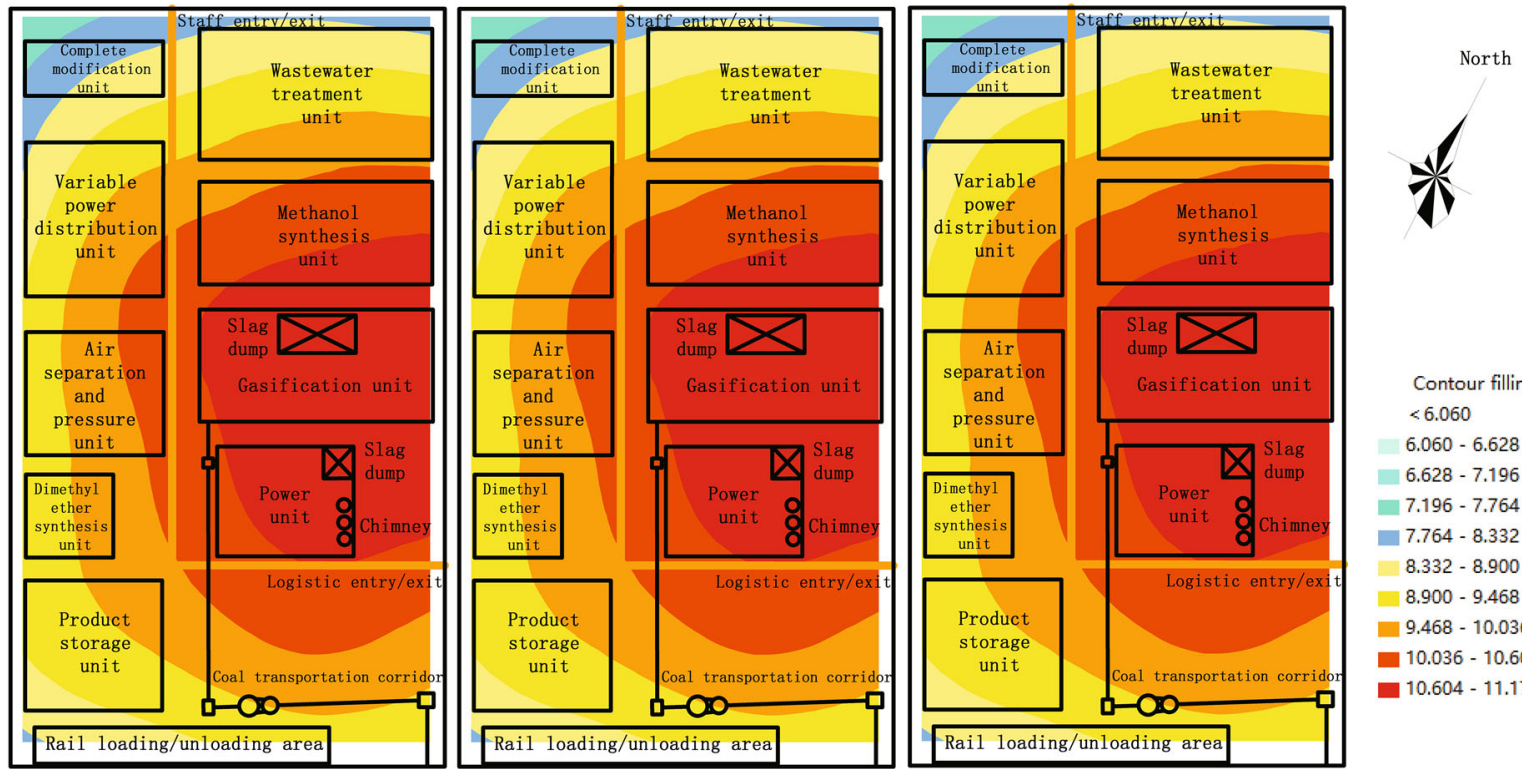

Contour filling

$<6.060$

$6.060-6.628$

$6.628-7.196$

$7.196-7.764$

$7.764-8.332$

$8.332-8.900$

$8.900-9.468$

$9.468-10.036$

$10.036-10.604$

$10.604-11.173$

Fig. 6 Spatiotemporal distribution of $\mathrm{Cr}(\mathrm{VI})$ concentrations in the soil of the coal chemical factory (left to right for the year 2021,2026 and 2031)

proposed to be the slag dumps of the power unit and gasification unit.

To control $\mathrm{Cr}(\mathrm{VI})$ pollution in the plant, the slag dump management of gasification units and power unit should be strengthened to control the dust and make good seepage prevention. Measures should be taken to protect staff members working in gasification unit and power unit from $\mathrm{Cr}(\mathrm{VI})$ hazards.

\subsubsection{Spatiotemporal change of As concentration and early warning}

In 2021, the high As concentration in the soil will cover the eastern part of the gasification unit, power units, main roads in the west-east direction, and the coal corridor. The As concentration is relatively uniform between 24.590 and $27.762 \mathrm{mg} / \mathrm{kg}$ (Fig. 7). In 2026, there would be a dropletlike area of As around the flue gas discharge and its southeastern side, where the concentration would be 

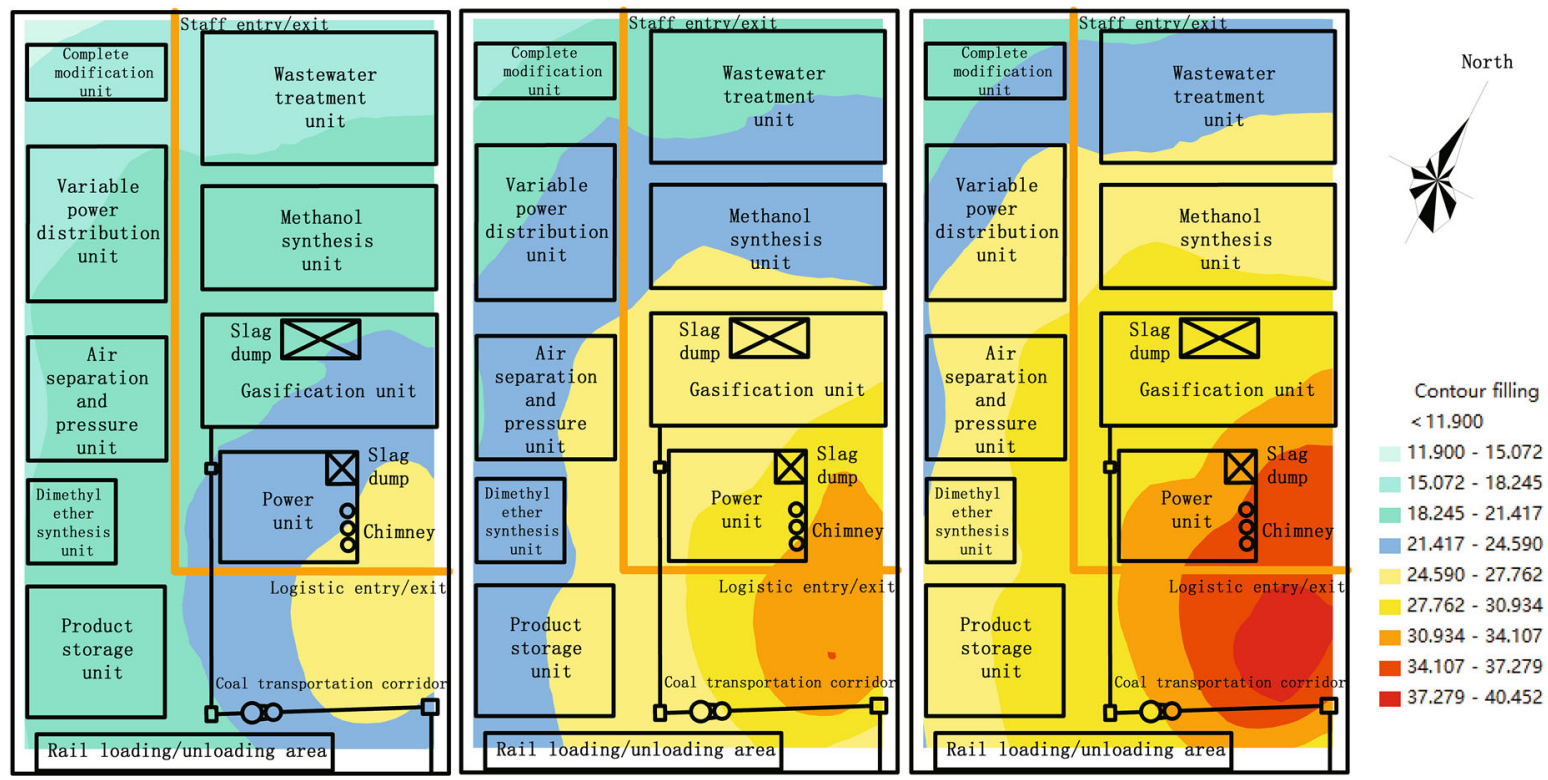

Fig. 7 Spatiotemporal distribution of As concentrations in the soil of the coal chemical factory (left to right for the year 2021, 2026 and 2031)

significantly higher than the high concentration in 2021. In 2031, the droplet-like area would be further highlighted with a shift to the southeast, and the As concentration would be further increased.

A study proposed that As was mainly converted into fly ash and gaseous oxides in coal combustion process ( $\mathrm{Lu}$ et al. 2003). In contrast, the main source of soil As in this plant in the present study was predicted to be coal-combustion flue gas emissions. The management of flue gas emissions and the control of the As emission should be strengthened to prevent and control the As contamination. For staff working in the gasification unit and its downwind direction, necessary protective measures should be taken to prevent As pollution hazards.

\section{Conclusions}

(1) The soil environmental capacity model was used to predict the HM concentrations in the coal chemical industry with parameters obtained by the leaching experiment. With the HM baseline values in 2011, the soil concentrations of $\mathrm{Pb}, \mathrm{Hg}, \mathrm{Cd}, \mathrm{Cr}$ and $\mathrm{As}$ in the year of 2021, 2026 and 2031 were predicted.

(2) The Kriging interpolation method was introduced with ArcGIS10.0 to achieve spatiotemporal simulations of the predicted HM concentrations in the soil. Spatiotemporal maps to predict the changing trends of HM concentrations were obtained. Prediction and early warning of HM pollution in the plant were also proposed.
(3) HMs can be rapidly enriched in the soil from discharge sources to the whole plant, due to the coal chemical industrial activities. The enrichment should be paid much attention both spatially and temporally.

(4) For the prevention and control of HMs in the plant, vehicle exhaust emissions along the traffic should be well controlled, lubricating oil should be used reasonably, and the friction of the transmission belt should be reduced. In addition, it is necessary to take measures to protect the staff working in the coal corridor and personnel commuting through the entrance and exit.

Also, the management of flue gas emissions in the plant area should be strengthened. Measures should be taken to protect staff members working under the flue gas discharge ports such as power units and logistics outlets.

Acknowledgements This work was co-supported by the Open Fund of State Key Laboratory of Water Resource Protection (SHJT-1630.8) and Utilization in Coal Mining and Research Funds for the Central Universities in China (2018QH03).

Open Access This article is distributed under the terms of the Creative Commons Attribution 4.0 International License (http://crea tivecommons.org/licenses/by/4.0/), which permits unrestricted use, distribution, and reproduction in any medium, provided you give appropriate credit to the original author(s) and the source, provide a link to the Creative Commons license, and indicate if changes were made. 


\section{References}

An Y, Zhang R, Yuan S, Jin H, Wang G, Pei X, Liu Y (2016) Health risk assessment of heavy metals in farmland soil in Hebei Province. Occup Health 32(9):1252-1255

Chen S (2014). Spatiotemporal modeling of heavy metal pollution in soil and its environmental risk warning. Dissertation, Central South University

Li Y (2011). Experimental study on emission and high-temperature control of trace elements during coal gasification. Dissertation, Huazhong University of Science and Technology

Li Y, Yu T, Li Y, Zhao Z (2014). Analysis of prediction model of soil heavy metal. In: Academic annual meeting of China Society of Environmental Science

Liang P, Li CX, Qin YC, Hu B, Jiang ZC (2000) Selective adsorption on nanometer size $\mathrm{TiO}_{2}$ powders for the chromium speciation using ICP-AES. J Anal Sci 16(4):300-303

Lin Y (2009). Pollution assessment and prediction of heavy metals in soil based on geostatistics and GIS. Dissertation, Central South University

Liu S (1987) Monitoring sample sites layout and collection of farmland soil. Agro-environ Prot 5:26-28

Liu Z, Cui X, Zhang S (2017) Study on environmental protection policy of modern coal chemical industry in China. Environ Impact Assess 39(2):1-4

Lu J, Sun J, Zhao C (2003) The occurrence of as in coal and its behavior during coal combustion. Coal Geol Explor 05:6-9

Shangguan Y, Qin X, Zhao D, Zhao L, Wang L, Hou H, Li F (2015) Migration and transformation of heavy metals in soils by lysimeter study with field condition. Res Environ Sci 28(7):1015-1024

Stewart MA, Jardine PM, Brandt CC, Barnett MO, Fendorf SE, McKay LD, Mehlhorn TL, Paul K (2003) Effects of contaminant concentration, aging, and soil properties on the bioaccessibility of $\mathrm{Cr}$ (III) and $\mathrm{Cr}(\mathrm{VI})$ in the soil. Soil Sediment Contam 12(1): $1-21$

Sun L, Bai Y (2008) Analysis of mass distribution and transformation of mercury in coal combustion in a coal-fired power plant. Clean Coal Technol 05:93-95

Tang GA, Yang X (2006) Experiment course of ArcGIS geographic information system spatial analysis. The Science Publishing Company, Beijing

Wang X (2012) Primary pollutants and pollution-control principles in coal chemical industry. Coal Chem Ind 40(5):38-42

Wang P (2014). Investigation and risk assessment of heavy metals pollution in soil on both side of some roads in Beijing.
Dissertation, Beijing University of Civil Engineering and Architecture

Wang S, Chu Y, Cai S (1993) Mathematical models of soil environmental capacity (I)-a dynamics model of soil pollution. Acta Sci Circumst 13(1):51-58

Wang C, Zheng W, Wang H, Zeng X, Ji S (2012) The relationship between heavy metals enrichment characteristics and soil acidification for environmental media in Yantai of Shandong province. Rock Miner Anal 31(2):361-369

Wu J, Zhang J, Xiao C (2016) Focus on factors affecting pH, flow of $\mathrm{Cr}$ and transformation between $\mathrm{Cr}(\mathrm{VI})$ and $\mathrm{Cr}(\mathrm{III})$ in the soil with different electrolytes. Electrochim Acta 211:652-662

Xia Z (1989) In soil environmental capacity and application. Meteorological Publishing House, Beijing

Xia X, Han X (2017) The present situation of coal chemical industry in China and suggestions on the development of coal chemical industry in Anhui Province. Anhui Chem Ind 43(3):9-12

Xu L, Cheng J, Zeng H (2004) Experimental investigation of the release characteristics of trace elements as, $\mathrm{Cd}$ and $\mathrm{Cr}$ during the combustion of coal. J Eng Therm Energy Power 19(5):478-482

Yang J, Huang L, Tang Y (2014) Leaching characteristics of metals from soil and vanadium titanomagnetite tailings. Environ Chem 33(3):440-446

Yi Y, Yang Z, Zhang S (2011) Ecological risk assessment of heavy metals in sediment and human health risk assessment of heavy metals in fishes in the middle and lower reaches of the Yangtze River basin. Environ Pollut 159(10):2575-2585

Zhang J, Zheng C, Liu J, Liu H (2003) Experimental study on the volatility of trace metals in coal combustion. J Eng Thermophys 24(6):1043-1046

Zhang K, Yang J, Bai L, Qiang C, Wang S (2017) The characteristics and source apportionment of heavy metal pollution in the soil at a coal chemical industry area in northwest China. J Min Sci Technol 2(2):191-198

Zhang K, Qiang C, Liu J (2018) Spatial distribution characteristics of heavy metals in the soil of coal chemical industrial areas. J Soils Sediments 3:1-9

Zhao J, Chen P, Zhang Z (1999) Study on the application of accumulation model of heavy metal in the soil in the environmental impact assessment of highway project. J Xi'an Highw Univ 19(4):58-61

Zhu S (1999). Preliminary study on spatial variability of soil physical and chemical properties. Dissertation, Beijing Normal University

Zhu M, Tang L, Liu D (2015) Monitor and risk assessment of heavy metals in the soils along the main road - A review. Environ Monit China 31(3):84-91 